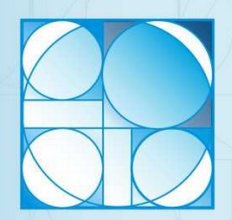

$2^{\circ}$ Prêmio Nacional de Ensino de Bioquímica e Biologia Molecular

Sociedade Brasileira de Bioquímica

e Biologia Molecular - SBBq
Journal of Biochemistry Education

Revista de Ensino de Bioquímica

Revista de Enseñanza de Bioquímica

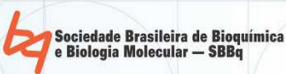

ISSN: 2318-8790

ISSN (until 2012): 1677-2318

14 a 17 de maio de 2019 - Águas de Lindóia, SP

\title{
"The Cell" and Learning Analytics: Users Performance Analysis in the Module "Chemical Composition of the Cell and Biological Membranes"
}

Macêdo, A.P.P.'; Galembeck, E. ${ }^{1}$

'Depto. de Bioquímica e Biologia Tecidual, IB - UNICAMP, SP, Brazil

INTRODUCTION: Learning Analytics tools aim to analyze data that allows the understanding of the learning process; its association with Massive Open Online Courses (MOOC) brings an opportunity for research into learning effectiveness, once MOOCs users produces digital footprints that can be used to understand their relationship with the content and environment. OBJECTIVES: To analyze the performance of users of "The Cell" in the module "Cell Chemical Composition and Biological Membranes" aiming to identify the major points that may have influenced their performance. MATERIALS AND METHODS: "Chemical Composition of the Cell and Biological Membranes" is a module of the MOOC "The Cell", a course designed into a 3D cell virtual model developed by the Laboratory of Educational Technologies of the Unicamp. The module is composed of textual content, challenge, training game, and assessment. "The Cell" has an embedded Statistical Analysis Module (SAM), an LA tool that collects data and has analysis tools focused on the student's performance and learning process. RESULTS AND DISCUSSION: Between November of 2015 and November of 2018, SAM has registered 2858 interactions involving 1114 users in the module. The average time to perform the training game was 3.45 minutes, and there was a significant difference in the scores average comparing users who did the activity below and above the average time: 54.10 and 70.44 points, respectively. A similar result was noticed for the assessment session, users who complete the task faster scored 48.83 on average, while users who take more time scored 52.83 on average. The average score in the assessment of users who did or did not took the training game was 51.20 and 36.75, respectively. CONCLUSION: The average time spent to carry out the activities is directly related to performance; the training game acts as a preparation for the assessment, reflected in the note.

Keywords: Learning Analytics, MOOC, teaching.

Supported by: This study was financed in part by the Coordenação de Aperfeiçoamento de Pessoal de Nível Superior - Brasil (CAPES) - Finance Code 001 